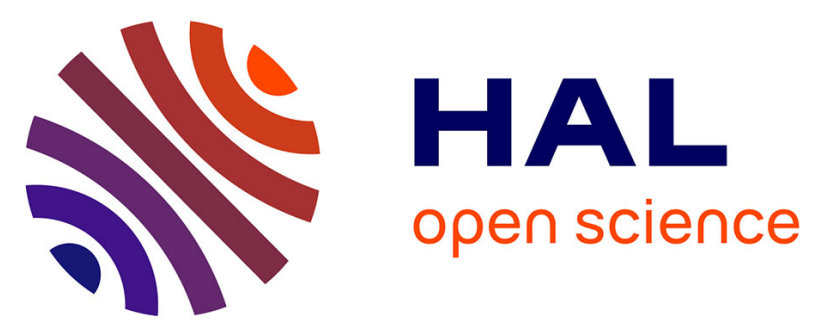

\title{
Metal Residues in Semiconducting Polymers: Impact on the Performance of Organic Electronic Devices
}

\author{
Özlem Usluer, Mamatimin Abbas, Guillaume Wantz, L. Vignau, Lionel
}

Hirsch, Eftychia Grana, Cyril Brochon, Eric Cloutet, Georges Hadziioannou

\section{- To cite this version:}

Özlem Usluer, Mamatimin Abbas, Guillaume Wantz, L. Vignau, Lionel Hirsch, et al.. Metal Residues in Semiconducting Polymers: Impact on the Performance of Organic Electronic Devices. ACS Macro Letters, 2014, 3 (11), pp.1134-1138. 10.1021/mz500590d . hal-02922703

\section{HAL Id: hal-02922703 \\ https://hal.science/hal-02922703}

Submitted on 26 Aug 2020

HAL is a multi-disciplinary open access archive for the deposit and dissemination of scientific research documents, whether they are published or not. The documents may come from teaching and research institutions in France or abroad, or from public or private research centers.
L'archive ouverte pluridisciplinaire HAL, est destinée au dépôt et à la diffusion de documents scientifiques de niveau recherche, publiés ou non, émanant des établissements d'enseignement et de recherche français ou étrangers, des laboratoires publics ou privés. 


\title{
Metal Residues in Semi-conducting Polymers: Impact on the Per- formance of Organic Electronic Devices
}

\author{
Özlem Usluer ${ }^{1,2}$, Mamatimin Abbas ${ }^{2 *}$, Guillaume Wantz ${ }^{2}$, Laurence Vignau ${ }^{2}$, Lionel Hirsch ${ }^{2}$, Eftychia \\ Grana $^{1}$, Cyril Brochon ${ }^{1}$, Eric Cloutet ${ }^{1 *}$, Georges Hadziioannou ${ }^{1}$ \\ ${ }^{1}$ Université de Bordeaux, Laboratoire de Chimie des Polymères Organiques (LCPO), CNRS (UMR5629), ENSCPB,16 ave- \\ nue Pey Berland, 33607 Pessac Cedex, France \\ ${ }^{2}$ Université de Bordeaux, Laboratoire de l'Intégration du Matériau au Système (IMS), CNRS (UMR5218), Site ENSCPB,16 \\ avenue Pey Berland, 33607 Pessac Cedex, France
}

KEYWORDS: Poly(3-hexylthiophene), metal residues, purification, organic field-effect transistor, organic solar cell

\begin{abstract}
The effect of impurities on the optoelectronic and charge transport properties of semi-conducting polymers was investigated through the performance of organic photovoltaics (OPVs) and organic field effect transistors (OFETs), respectively. A model representative semi-conducting polymer, i.e. poly(3-hexylthiophene) (P3HT), was synthesized and purified using different methods such as precipitation, metals' complexation, and Soxhlet extraction. After the purification processes, each fraction was analyzed to determine its composition in metals (impurities) by various techniques. OFETs and OPVs fabricated from these purified polymer fractions were found to show different charge carrier properties and photovoltaic behaviors. The purest fraction which was obtained after soxhlet extraction complemented by metals' complexation with the help of ethylenediamine and 15-crown-5 ether showed the best performance in both OPVs and OFETs.
\end{abstract}

Semi-conducting polymers have been extensively investigated over the last few decades due to their potential applications in organic photovoltaic cells (OPVs), ${ }^{1,2}$ organic light emitting diodes (OLEDs), ${ }^{3,4}$ organic field-effect transistors (OFETs) $)^{5,6}$ and sensors. ${ }^{7}$ The synthesis of the $\pi$-conjugated polymers mainly dealing with cross-coupling reaction routes (e.g. Suzuki, Stille, Yamamoto, Kumada, Negishi, Sonogashira, Heck, etc.) or oxidative polymerizations, often involves transition metal-based materials as catalysts. ${ }^{8}$ After polymerization, depending on the reactions and purification procedures, different types of metals such as $\mathrm{Ni}, \mathrm{Pd}, \mathrm{Fe}, \mathrm{Sn}, \mathrm{Pt}, \mathrm{Cd}, \mathrm{Mg}, \mathrm{Na}, \mathrm{K}$ etc., may remain in the final raw material. Residual catalysts and other organic or inorganic impurities present in the polymers may act as charge carrier traps or photo-quenchers affecting strongly their intrinsic properties, consequently reducing the performance of the optoelectronic devices. ${ }^{9-13}$ Residual metal ions in the $\pi$-conjugated polymer can also cause leakage current in the optoelectronic devices and reduce device efficiency and stability. Finally, impurities can also affect the solubility of $\pi$-conjugated polymers by causing aggregation. ${ }^{14}$

Procedures have been reported to remove metallic residues from polymers. Washing with polar solvents and/or selective organic solvents via Soxhlet extraction is a common purification method. Metal chelating agents, crown ethers and ionic complexing agents are also used to remove metallic residues from conducting polymers. ${ }^{15,16}$ Metal chelating agents are ligands known to bind a metal at two or more sites. The most widely used chelating agents are those that coordinate to metal ions through oxygen or nitrogen donor atoms, or both. For instance, ethylenediamine, ethylenediamine tetraacetic acid and dimethylglyoxime were used as chelating agents. ${ }^{17}$ Crown ethers are cyclic chemical compounds that consist of a ring containing several ether groups that can also be used as metal chelating agents. Crown ether molecules can trap metal ions by forming ion-dipole bonds with them. The ring size as well as the number and the type of heteroatoms are very important parameters for the connection with the metal ions. For instance, 18-crown-6 has high selectivity for $\mathrm{K}^{+}, 15$-crown-5 for $\mathrm{Na}^{+}$and 12-crown-4 for $\mathrm{Li}^{+}{ }^{18}$

The effects of organic dopants on the performance of OPVs ${ }^{19}$ and OFETs, ${ }^{20}$ along with the effect of doping with metal complex on OPV devices have recently been investigated. ${ }^{21}$ Nevertheless, a study on the impact of residual metals, left from different purification processes, for both OFET and OPV devices has yet to be systematically carried out and a suitable purification process in achieving a polymer fraction which works best for devices should be identified. 
In this work, the influence of metal residues and purification process of P3HT, used as a semi-conducting polymer model, on OFET characteristics and OPV device performance was investigated in order to identify the optimal purification procedure suited to the best performing polymer fraction in both devices and to explore the intrinsic properties of the semiconducting polymers. P3HT polymer samples were synthesized via a nickel complex catalyst transfer chain-growth polymerization route and purified using various procedures. The latter combined precipitation, metals' complexation using metals' scavengers and chelating agents such as dimethylglyoxime, ethylenediamine, crown ether derivatives and finally Soxhlet extraction with different ultra pure solvents (such as hexane, methanol and chloroform). After each purification process, all polymer fractions were characterized and analyzed to determine their structure as well as their composition in metallic residues by various techniques. The performance of the various purified semi-conducting polymer fractions in OPV and OFET devices was studied. The best purified fraction in terms of metallic residues was found to show high PCE in OPVs and low hysteresis together with high on/off current ratio in OFETs.

The synthesis of poly(3-hexylthiophene) (P3HT) polymers were conducted following a well-established procedure which uses the Grignard metathesis method (GRIM) also called transition metal-catalyzed chain-growth polymerization. ${ }^{22}$ The polymers were purified by using metal complexing agents and consecutive washings using the Soxhlet technique with methanol, hexane and chloroform, respectively (Scheme 1). After each purification method, polymer fractions were analyzed with SEC, ${ }^{1} \mathrm{H}$ NMR and ICP-MS. ${ }^{1} \mathrm{H}$ NMR spectra were recorded for each fraction of P3HT. There was no significant difference among the NMR spectra of P3HT fractions (see in Supporting Information Fig. S1).

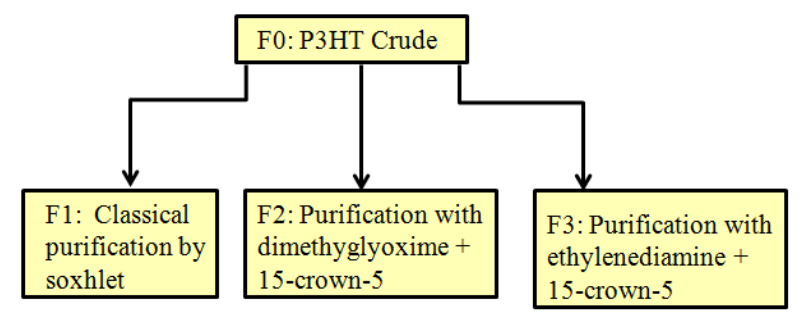

Scheme 1. The purification methods of P3HT.

Results obtained from SEC characterization (in $\mathrm{CHCl}_{3}$, RI detector, polystyrene standards calibration) are provided in Table 1.

The macromolecular features of all P3HT fractions are consistent with the different purification stages achieved from the raw $\mathbf{F 0}$ fraction. In fact, high dispersity values arise from the initial Fo fraction which was around 1.8 and the soxhlet procedure usually results in an increase in molecular weight together with a decrease in the dispersity of the semiconductor polymer when going from bad to good solvents (see in Supporting Information Fig. S2).
Table 1. Macromolecular characteristics of $\mathrm{P} 3 \mathrm{HT}$ fractions obtained from SEC Analysis (in $\mathrm{CHCl}_{3}$, PS calibration).

\begin{tabular}{|c|c|c|c|c|}
\hline & Fo & F1 & F2 & F3 \\
\hline Mn [g.mol $\left.{ }^{-1}\right]$ & 13080 & 23650 & 24420 & 32390 \\
\hline Mw [g.mol $\left.{ }^{-1}\right]$ & 23730 & 37050 & 40140 & 44940 \\
\hline Đ & 1.8 & 1.6 & 1.6 & 1.4 \\
\hline
\end{tabular}

The amount of residues in each fraction of P3HT was determined by ICP-MS and all data for several elements are shown in the Table 2. ICP-MS analyses clearly show a variation of the composition depending on the purification methods. Ni, $\mathrm{Mg}$ and $\mathrm{Na}$ were introduced during the monomer and polymer synthesis multistep process, with reagents, catalysts or even drying agent $\left(\mathrm{Na}_{2} \mathrm{SO}_{4}\right)$. The other metals $\mathrm{Fe}, \mathrm{K}, \mathrm{Cu}, \mathrm{Ca}$ and $\mathrm{Zn}$ might come from reagents and solvents, which were used asreceived without further purification. According to ICP-MS data, F0 fraction (crude product) has the highest level of contamination. After classical purification (F1, soxhlet extraction with methanol, hexane, and chloroform) most of metallic residues have been removed from the polymers. Purification by using dimethylglyoxime supplemented with 15 -crown-5 ether (F2) do not decrease the level of metal residues in regard to the classical purification (F1). The purification consisting in the combination of ethylenediamine and crown ether as chelating agents (F3) seems more efficient than purification associating dimethylglyoxime and crown ethers (F2). This is particularly the case for the reduction of alkali ions (e.g. $\mathrm{Na}^{+}$and $\mathrm{K}^{+}$). It is noteworthy that the purest P3HT fractions are recovered in chloroform after several purification stages including metal scavengers and soxhlet extraction. All fractions were therefore collected and studied in organic field effect transistor and solar cell devices in order to correlate the "purity" of the semi-conducting polymer or the purification methodology to their performance in organic electronic devices.

When it comes to the quality of OFET devices, hysteresis and on/off current ratio are the prime parameters, as they concern the stability and sensitivity of the device, essential for OFETs as active components in circuits and sensors. Among six devices fabricated for each fraction of polymer as active layers, the devices with the minimum hysteresis were chosen as the best performing ones. When hysteresis was similar, highest on/off current ratio was used as the second criterion. A typical transfer characteristic in the saturation regime of the OFET device with F0 (crude product) and F3 (purest) fraction as active layers is shown in Figure 1b. Derived device parameters such as threshold voltage $\left(\mathrm{V}_{\text {th }}\right)$ hysteresis $\left(\Delta \mathrm{V}_{\text {th }}\right)$ and on/off current ratio could be extracted from Figure 1b. Mobilities were estimated from the maximum of the gate voltage dependent mobility curves. The comparison of these parameters for the different fractions is displayed in Figure 2. 
Table 2. ICP-MS data for all fractions of P3HT polymers according to the purification stage.

\begin{tabular}{|c|c|c|c|c|c|c|c|c|}
\hline \multirow[t]{2}{*}{ Sample } & \multicolumn{8}{|c|}{ Analyte Concentration (ppm) } \\
\hline & $\mathbf{N i}$ & $\mathbf{F e}$ & $\mathbf{K}$ & Mg & $\mathbf{C u}$ & $\mathbf{C a}$ & $\mathbf{N a}$ & $\mathbf{Z n}$ \\
\hline F0 & 0.61 & 4.28 & 5.54 & 1.81 & 0.57 & 4.08 & 16.39 & 0.98 \\
\hline F1 & 0.13 & 2.20 & 0.7 & 0.36 & 0.10 & 1.4 & 3.74 & 0.15 \\
\hline F2 & 0.13 & 2.50 & 2.58 & 0.46 & 0.29 & 2.80 & 6.94 & 0.18 \\
\hline F3 & 0.02 & 2.05 & 0.53 & 0.04 & 0.23 & 0.40 & 1.69 & 0.13 \\
\hline
\end{tabular}

(a)

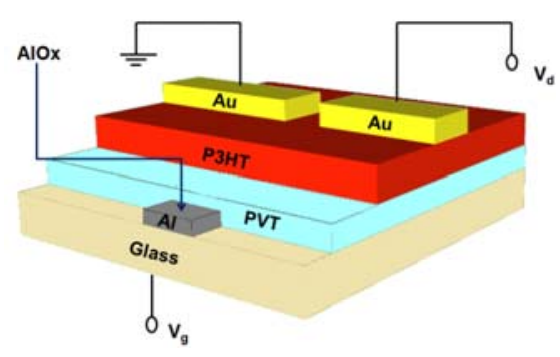

(b)
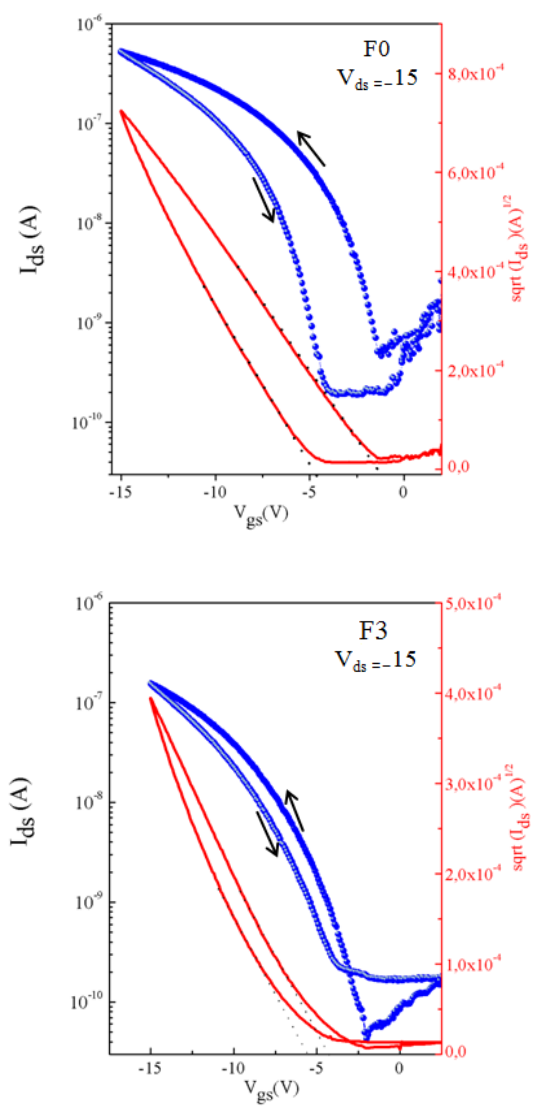

Figure 1. a) Bottom gate, top-contact field-effect transistor device used in this work, b) transfer characteristics of the OFET devices in saturation regime with F0 and F3 as the active layer. Threshold voltage was determined by extrapolating sqrt $\left(\mathrm{I}_{\mathrm{ds}}\right)$ to zero current. Hysteresis was quantified by the difference in the threshold voltages $\left(\Delta \mathrm{V}_{\mathrm{th}}\right)$ of forward and backward scan as shown in the figure as dashed lines.
Molecular weight and dispersity $\left(\mathrm{D}=\mathrm{M}_{\mathrm{w}} / \mathrm{M}_{\mathrm{n}}\right)$ of P3HT are known to have significant effect on the charge carrier mobility. While smaller molecular weight polymer thin films tend to crystallize better with enhanced grain boundaries, high molecular weight polymer thin films show more amorphous but interconnected network character. Higher macromolecular dispersity allows for the combination of these two cases with crystalline zones efficiently connected by amorphous zones leading to higher charge carrier mobility. ${ }^{23}$ Therefore, in our different fractions through various purification processes, the resultant differences in molecular weight and dispersity are important parameters affecting device performance, especially the mobility.
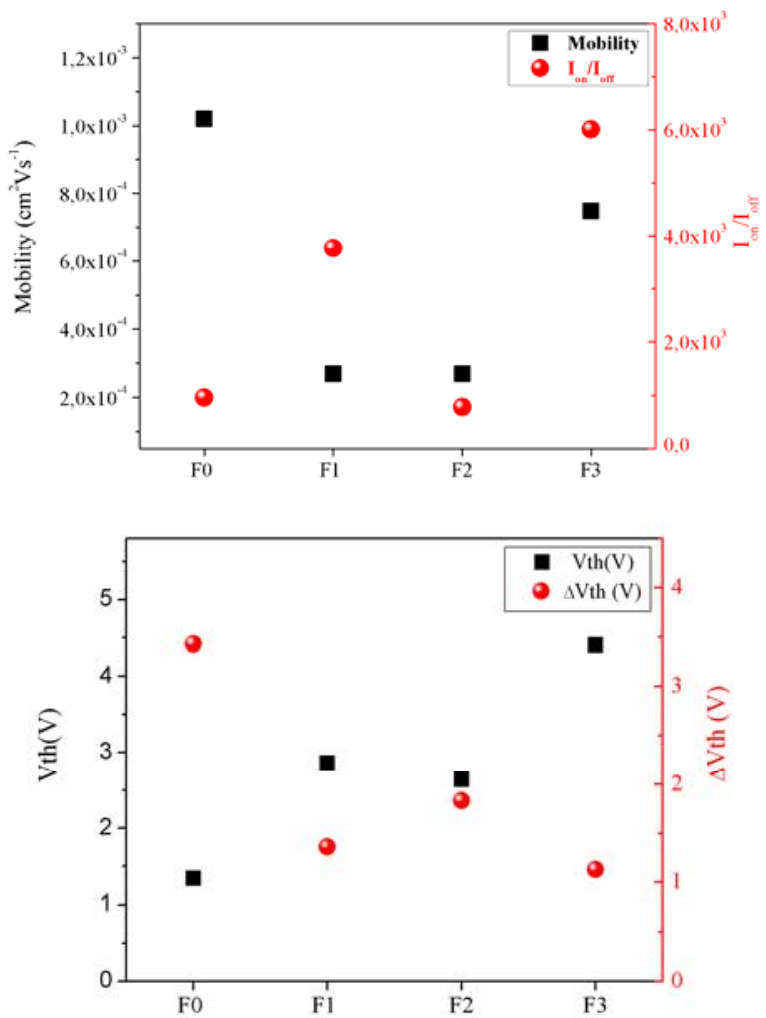

Figure 2. OFET device parameters for all P3HT fractions.

While having the lowest molecular weight and the higher level of metallic contamination, the crude product $(\mathbf{F 0})$ shows relatively high mobility $\left(1 \times 10^{-3} \mathrm{~cm}^{2} \mathrm{Vs}^{-1}\right)$. In that specific case, not 
only the purity plays a role but also the high dispersity value (i.e. $Đ \sim 1.8$ ) which facilitates interconnection between crystal domains. ${ }^{9}$ When classical purification was used (F1), the obtained high molecular weight (i.e. $\mathrm{Mw} \sim 37 \mathrm{k}$ ) together with a relatively lower dispersity value (i.e. $Đ \sim 1.6$ ) can be the causes of the decreased mobility $\left(2.7 \times 10^{-4} \mathrm{~cm}^{2} \mathrm{Vs}^{-1}\right)$ in regard to the crude product. Polymer fraction issued from purifications with dimethylglyoxime plus 15-crown-5 (F2), despite showing quite different degree of ionic impurities content, it exhibits comparable mobilities as that of $\mathbf{F 1}$, as their molecular weight and dispersity values are similar. The purification method consisting in combining ethylenediamine and 15-crown-5 ether (F3) led to a higher mobility $\left(7.5 \times 10^{-4} \mathrm{~cm}^{2} \mathrm{Vs}^{-1}\right)$. This is caused by a significantly higher molecular weight $(\mathrm{Mw} \sim 45 \mathrm{k})$ overweighting the role of lower dispersity (i.e. $Đ \sim 1.4$ ). Therefore, when it comes to the mobilities of different polymer fractions, molecular weight and dispersity play determining role comparing to the amount of metal residues, as positive ions do not act as trapping species for hole charge transport in p-channel layer. They do, however, contribute to the current: notably high concentration results in elevated $\mathrm{I}_{\mathrm{off}}$, and early switching on of the channel through filling hole trapping sites, thus leading to lower threshold voltage $\left(\mathrm{V}_{\text {th }}\right) .{ }^{24} \mathrm{~A}$ general trend of increased $\mathrm{V}_{\text {th }}$ was observed, when ionic impurities were decreased. F3 fraction as the purest fraction evidenced highest $\mathrm{V}_{\text {th. }}$.

Ionic impurities should have strong effect on the hysteresis behavior of the device, as the ion transport is much slower than charge transport. Indeed we have observed the biggest hysteresis $\left(\Delta \mathrm{V}_{\mathrm{th}}=3.4 \mathrm{~V}\right)$ in the crude product $(\mathbf{F 0})$ (see Figure 2). F1 fraction with classical purification process led to a remarkable decrease in hysteresis. However, $\mathbf{F 3}$ fraction again show enlarged hysteresis, which can be attributed to the fact that the addition of dimethylglyoxime together with 15-crown5 ether was not as efficient as classical purification in eliminating the ionic impurities. Hysteresis decreased to the minimum in the case of $\mathbf{F 3}$ fraction owing to the lowest amount of contamination level when comparing to all other fractions.

Finally, on/off current ratio also strongly depends on the effect of ionic residues as shown in Figure 2. High concentration of ionic impurities leads to elevated $\mathrm{I}_{\text {off, }}$ thus resulting in low on/off current ratio, as in the case of crude product (F0). Evidently, we have achieved the highest on/off current ratio from the F3 fraction, which contains the lowest amount of metals, notwithstanding its moderate mobility.

In this respect, we can claim that by decreasing the ionic impurities to the lowest amount, we managed to achieve the best performing OFET devices. In the following we have investigated the role of P3HT contamination when integrated within a common bulk heterojunction organic solar cell architecture in the presence of PCBM acceptor even though the purity of the latter was not checked.

In order to investigate the effect of impurities in P3HT on photovoltaic performance, bulk heterojunction solar cell devices were fabricated and tested with all P3HT fractions issued from the different purification methods. The devices with the highest power conversion efficiency (PCE) were chosen among eight devices for each fraction. Figure $3 \mathrm{~b}$ shows the $\mathrm{J}-$ $\mathrm{V}$ curves of the fabricated solar cells. Figure 4 shows the pho- tovoltaic parameters under AM1.5 illumination for the best solar cell device of each fraction of P3HT:PCBM blend.

(a)

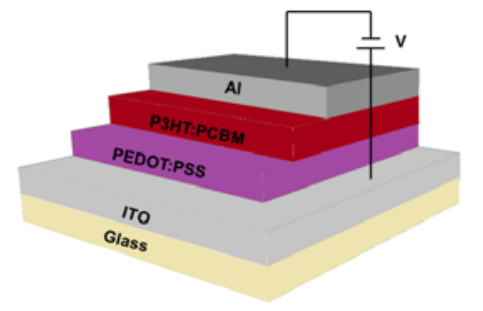

(b)

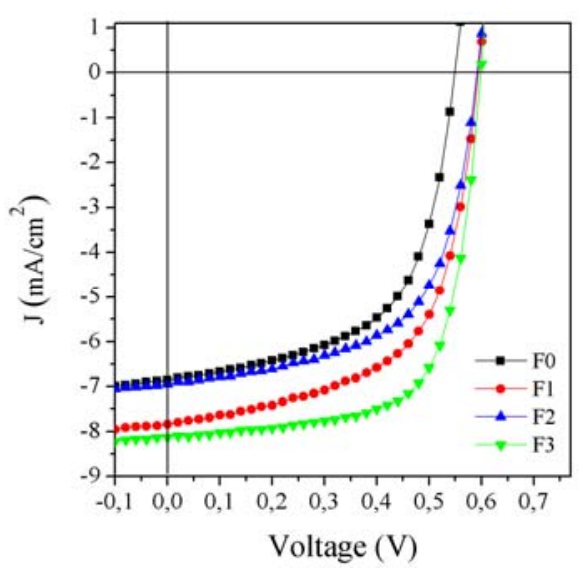

Figure 3. a) Bulk heterojunction solar cell device architecture used in this work, b) J-V curves of solar cells utilizing P3HT:PCBM blends (1:0.7 weight ratio).

The effect of mobility variation due to the difference in the molecular weight and dispersity of the polymers on the OPV device performance is not substantial, as proved by $\mathbf{F} 1$ fraction which yields higher power conversion efficiency $(2.78 \%)$ than F0 $(2.18 \%)$ even though the former has relatively lower mobility than the latter. This allows us to observe the direct effect of ionic impurities on OPV device performance. As both holes and electrons are transported in the active layer, any type of ion can act as a recombination center for the two types of charges. For instance, it can be observed that increased recombination deteriorates the short circuit current density $\left(\mathrm{J}_{\mathrm{sc}}\right)$ and open circuit voltage. Indeed, we have detected very good agreement between $J_{\mathrm{sc}}$ values and the amount of metallic residues in the different fractions. The $\mathrm{J}_{\mathrm{sc}}$ increased from the lowest value of $6.86 \mathrm{mAcm}^{-2}$ in the crude product $(\mathbf{F O})$ to the highest one being $8.13 \mathrm{mAcm}^{-2}$ in the purest fraction $(\mathbf{F 3})$. Besides, the open circuit voltage $\left(\mathrm{V}_{\mathrm{oc}}\right)$ can consistently decline when trap-assisted recombination is significant enough in regard to high ionic impurity concentration. This could be the reason for the low $\mathrm{V}_{\text {oc }}(0.54 \mathrm{~V})$ we obtained in the case of the crude product (F0). If concentrations of metal residues are decreased to a certain level, intrinsic recombination mechanisms dominate in the devices and yield rather similar $\mathrm{V}_{\text {oc }}$ values for the other fractions. Added to charge trapping, the presence of ions can also lead to greater leakage current from the diode, effectively decreasing shunt resistance. This can 
eventually cause fill factor (FF) compensation. While crude product (F0) yielded only $58 \%$ of FF, we obtained the highest FF $(68 \%)$ for the purest fraction (F3), one of the highest values reported for P3HT:PCBM-based OPV devices. Thus, the fraction bearing the lowest ionic impurity concentration evidenced the best device performance parameters with a PCE of $3.32 \%$ compared to $2.18 \%$ for the crude product.
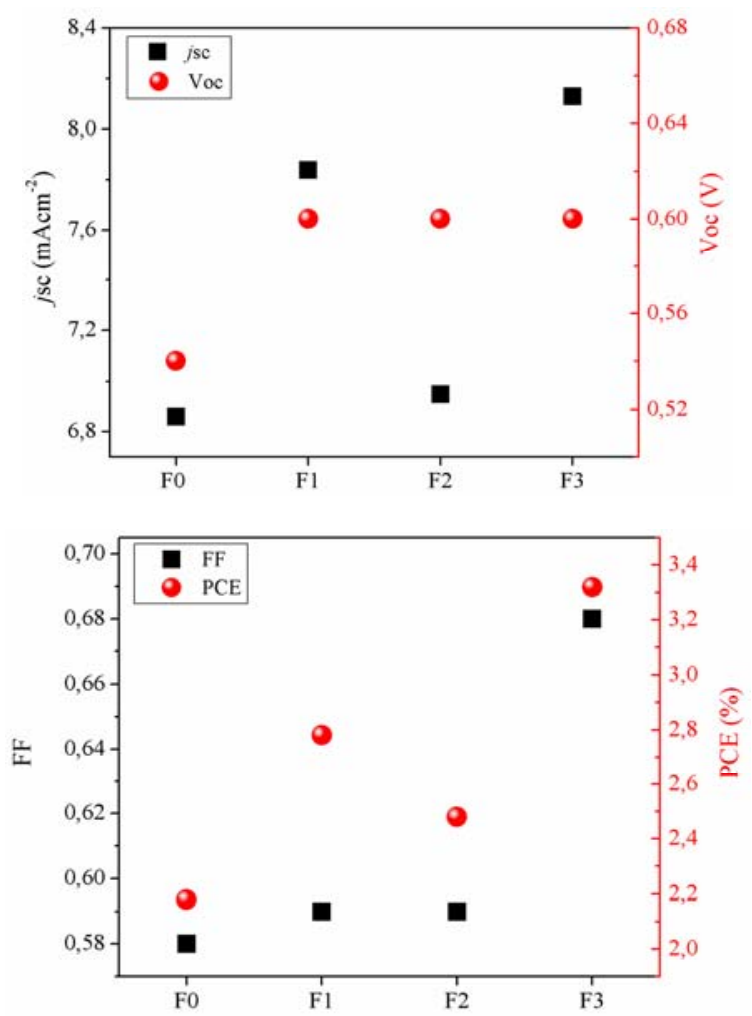

Figure 4. Photovoltaic device performance parameters of the solar cells fabricated from each fraction of P3HT:PCBM blends.

In summary, we have studied the effect of ionic metal residues present in freshly synthesized and purified P3HT polymer on OFETs and OPVs. Importantly, different purification methodologies were developed so as to evaluate the best one. Classical purification (F1, Soxhlet extraction with methanol, hexane, and chloroform) proved to be quite efficient in removing most of the ionic impurities. Among the various systems studied in this work it appears that the combination of metal scavengers based on polyamine and cyclic polyethers derivatives (i.e. ethylenediamine plus 15 -crown-5 ether) gives rise to the lower level of metallic contamination within the semi-conducting poly(3-hexylthiophene) (P3HT). For instance, we have achieved the best operating OFET device with the lowest hysteresis and the highest $\mathrm{I}_{\mathrm{on}} / \mathrm{I}_{\text {off }}$ ratio from the device based on the purest fraction (F3). This fraction also showed the best performance in OPV devices with PCE of $3.32 \%$ in regard to $2.18 \%$ using the crude product. This work will bring a deeper understanding on how impurities affect the electrical properties of organic electronic devices.

\section{AUTHOR INFORMATION}

\section{Corresponding Author}

*E-mail: mamatimin.abbas@ims-bordeaux.fr;

cloutet@enscbp.fr

Notes

The authors declare no competing financial interest.

\section{ACKNOWLEDGMENTS}

This work was supported by the LabEx AMADEus (ANR-10LABX-42) in the framework of IdEx Bordeaux (ANR-10IDEX-03-02) i.e. the Investissements d'Avenir programme of the French government managed by the Agence Nationale de la Recherche. The authors thank Mélanie Bousquet for GPC measurement.

Supporting Information Available: Experimental details. This material is available free of charge via the Internet at http://pubs.acs.org.

\section{REFERENCES}

(1) (a) Sariciftci, N. S.; Smilowitz, L.; Heeger, A. J.; Wudl, F. Science 1992, 258, 1474. (b) Günes,S.; Neugebauer, H.; Sariciftci, N. S. Chem. Rev. 2007, 107, 1324.

(2) (a) Tore, N.; Alturk Parlak, E.; Usluer, O.; Egbe, D. A. M.; San, S. E.; Aydogan, P. Solar Energy Materials \& Solar Cells 2012, 104, 39. (b) Kösemen, A.; Tore, N.; Alturk Parlak, E.; Alpaslan Kösemen, Z.; Ulbricht, C.; Usluer, O.; Egbe, D. A. M.; Yerli, Y.; San, S. E. Solar Energy 2014, 99, 88. (c) Troshin, P. A.; Mukhacheva, O. A.; Usluer, O.; Goryachev, A. E.; Akkuratov, A. V.; Susarova, D. K.; Dremova, N. N.; Rathgeber, S.; Sariciftci, N. S.; Razumov, V. F.; Egbe, D. A. M. Adv. Energy Mater. 2013, 3, 161.

(3) (a) Friend, R. H.; Gymer, R. W.; Holmes, A. B.; Burroughes, J. H.; Marks, R. N.; Taliani, C.; Bradley, D. D. C.; Dos Santos, D. A.; Bredas, J. L.; Lögdlund, M.; Salaneck, W. R. Nature 1999, 397, 121. (b) Berggren, M.; Inganas, O.; Gustafsson, G.; Rasmusson, J.; Andersson, M. R.; Hjertberg, T.; Wennerstrom, O. Nature 1994, 372, 444.

(4) (a) Usluer, O.; Kastner, C.; Abbas, M.; Ulbricht, C.; Cimrova, V.; Wild, A.; Birckner, E.; Tekin, N.; Sariciftci, N. S.; Hoppe, H.; Rathgeber, S.; Egbe, D. A. M. J. Polym. Sci., Part A: Polym.Chem. 2012, 50, 3425. (b) White, M.; Kaltenbrunner, M.; Glowacki, E.; Gutnichenko, K.; Kettlgruber, G.; Graz, I.; Aazou, S.; Ulbricht, C.; Egbe, D. A. M.; Miron, M. C.; Major, Z.; Scharber, M. C.; Sekitani, T.; Someya, T.; Bauer, S.; Sariciftci, N. S. Nature Photonics 2013, 7, 811.

(5) Sirringhaus, H. Advanced Materials 2005, 17, 2411.

(6) Hamadani, B. H.; Natelson, D. Applied Physics Letters 2004, 84, 443.

(7) (a) Bai, H.; Shi, G. Sensors 2007, 7, 267. (b) Knopfmacher, O.; Hammock, M. L.; Appleton, A. L.; Schwartz, G.; Mei, J.; Lei, T.; Pei, J.; Bao, Z. Nature Communications 2014, doi:10.1038/ncomms3954.

(8) (a) McCullough, R. D. Adv. Mater. 1998, 10, 93. (b) Carsten, B.; He, F.; Son, H. J.; Xu, T.; Yu, L. Chem. Rev. 2011, 111, 1493. (c) Yokozawa, T.; Yokoyama, A. Chem. Rev. 2009, 109, 5595.

(9) Urien, M.; Wantz, G.; Cloutet, E.; Hirsch, L.; Tardy, P.; Vignau, L.; Cramail, H.; Parneix, J. P. Organic Electronics 2007, 8, 727. 
(10) Camaioni, N.; Tinti, F.; Franco, L.; Fabris, M.; Toffoletti, A.; Ruzzi, M.; Montanari, L.; Bonoldi, L.; Pellegrino, A.; Calabrese, A.; Po, R. Organic Electronics 2012, 13, 550.

(11) Cowan, S. R.; Leong, W. L.; Banerji, N.; Dennler, G.; Heeger, A. J. Adv. Funct. Mater. 2011, 21, 3083.

(12) Nikiforov, M. P.; Lai, B.; Chen, W.; Chen, S.; Schaller, R. D.; Strzalka, J.; Maserb, J.; Darling, S. B. Energy Environ. Sci. 2013, 6, 1513.

(13) Ashraf, R. S.; Schroeder, B. C.; Bronstein, H. A.; Huang, Z.; Thomas, S.; Kline, R. J.; Brabec, C. J.; Rannou, P.; Anthopoulos, T. D.; Durrant, J. R.; McCulloch, I. Adv. Mater. 2013, 25 , 2029.

(14) Chen, K. Y.; Tuan, C. S.; Teng, W. J.; Chang, S. J. United States Patent Application Publication, 2004, US 2004/0250849 A1.

(15) Xiao; S. S.; Qui, C.; Qui, X. United States Patent Application Publication, 2004, US 2004/0254336 A1.

(16) Mccullough, R. D.; Iovu, M. C.; Bent, S. A. World Intellectual Property Organization 2008, WO 2008/063731 A2.

(17) Flora, S. J. S. ; Pachauri, V. Int. J. Environ. Res. Public Health 2010, 7, 2745.

(18) Steed, J. W. Coordination Chemistry Reviews 2001, 215, 171.

(19) Kaake, L.; Dang, X.-D.; Leong, W. L.; Zhang, Y.; Heeger, A.; Nguyen, T. -Q. Adv. Mater. 2013, 25, 1706.

(20)Olthof, S.; Singh, S.; Mohapatra, S. K.; Barlow, S.; Marder, S. R.; Kippelen, B.; Kahn, A. Appl. Phys. Lett. 2012, 101, 253303.

(21) Nikiforov, M. P.; Lai, B.; Chen, W.; Chen, S.; Schaller, R. D.; Strzalka, J.; Maser, J.; Darling, S. B. Energy and Environmental Science, 2013, 6, 1513 .

(22) (a) Iovu, M. C.; Jeffries-EL, M.; Sheina, E. E.; Cooper, J. R.; McCullough, R. D. Polymer 2005, 46, 8582.; (b) Iovu, M. C.; Sheina, E. E.; Gil, R. R.; McCullough, R. D. Macromolecules 2005, 38, 8649. (c) Yokoyama, A.; Miyakoshi, R.; Yokozawa, T. Macromolecules, 2004, 37, 1169.

(23) (a) Ma, W.; Kim, J. Y.; Lee, K.; Heeger, A. J. Macromol. Rapid Commun. 2007, 28, 1776. (b) Hiorns, R. C.; de Bettignies, R.; Leroy, J.; Bailly, S.; Firon, M.; Sentein, C.; Khoukh, A.; Preud'homme, H.; Dagron-Lartigau, C. Adv. Funct. Mater. 2006, 16, 2263. (c) Nicolet, C.; Deribew, D.; Renaud, C.; Fleury, G.; Brochon, C.; Cloutet, E.; Vignau, L.; Wantz, G.; Cramail, H.; Geoghegan, M.; Hadziioannou, J. Phys. Chem. B, 2011, 115, 12717.

(24) Abbas, M.; Cakmak, G.; Tekin, N.; Kara, A.; Guney, H. Y.; Arici, E.; Sariciftci, N. S. Organic Electronics, 2011, 12, 497. 


\section{Table of Contents (TOC)}

Different purification processes are used to purify semi-conducting polymer from trace metal impurities. The best approach is identified for obtaining the purest fraction, based on which, highest power conversion efficiency from organic solar cells and best performing organic field effect transistors with smallest hysteresis as well as highest current on/off ratio are achieved.
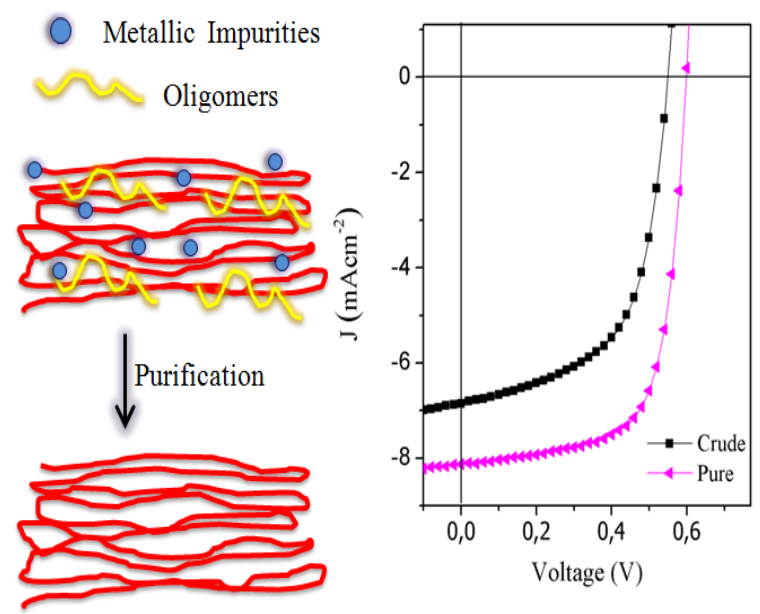